\title{
Considerações Sobre a Reciclagem de Embalagens Plásticas
}

\author{
Flávio J. Forlin, José de Assis F. Faria \\ Departamento de Tecnologia de Alimentos, FEA, UNICAMP
}

Resumo: Este artigo aborda considerações atualizadas sobre a reciclagem de embalagens plásticas com foco no setor de alimentos. No contexto mundial é avaliado o crescente volume de utilização de embalagens plásticas na preservação de alimentos e levantados os componentes sanitários, mercadológicos, sócio-econômicos e ambientais associados. São avaliadas como potenciais vias de reciclagem a transformação mecânica de embalagens plásticas em novos materiais ou produtos, a recuperação de resinas, a transformação térmica, a reutilização de embalagens e a degradação ambiental. O contexto brasileiro mostra potenciais características de viabilidade sócio-econômica e empresarial para a reciclagem de embalagens plásticas, exigindo, todavia, maior conjunção de ações governamentais, empresariais e de pesquisa no setor.

Palavras-chave: Reciclagem, embalagens plásticas, alimentos.

\section{Considerations About Packing Plastics Recycling}

Abstract: This article addresses up-to-date considerations on the recycling of packing plastics, with focus on the food sector. In the worldwide context, an evaluation is provided of the increase in the volume of packing plastics for food preservation and comments are made on the associated sanitary, marketing, social, economic and environmental aspects. Potential recycling ways for packing plastics are evaluated, such as the mechanic transformation in new materials or products, resin recuperation, thermal transformation, packing refill and environmental degradation. The Brazilian context points to a potential viability of the recycling of packing plastics in terms of economical, social and marketing aspects. An efficient recycling industry demands, however, concerted actions from government and companies, in addition to further research in this field.

Keywords: Recycling, packing plastics, foods.

\section{Introdução}

A reciclagem de embalagens plásticas preocupa a sociedade, mundialmente, face ao crescente volume de utilização e as implicações ambientais inerentes ao seu descarte não racional pós-consumo, como no setor de alimentos.

Os hábitos de consumo da sociedade moderna, a definição de regulamentações específicas, a implementação de centros de pesquisa e o desenvolvimento de tecnologias adequadas, constituem pauta de ações específicas de setores governamentais e empresariais na reciclagem de embalagens.
A rentabilidade do mercado de reciclagem de embalagens plásticas no Brasil, como em outros países desenvolvidos, mostra aspectos atraentes para iniciativas empresariais do setor, com reflexos sócio-econômicos diretos relacionados com a melhoria da qualidade de vida da população, geração de renda, economia de recursos naturais e atenuação de problemas ambientais.

A consolidação e o incremento do volume dos materiais plásticos utilizados em embalagens na vida moderna representa um desafio sob o ponto de vista da sua reciclagem racional, exigindo uma abordagem integrada entre os processos de transformação das

Autor para correspondência: José de Assis F. Faria, Departamento de Tecnologia de Alimentos, FEA, UNICAMP, Caixa Postal 6121, CEP: 13081-970, Campinas, SP. E-mail:jaff@fea.unicamp.br 
matérias-primas, fabricação das embalagens e sua funcionalidade na conservação do produto.

Panorama brasileiro e mundial da utilização de embalagens

Os principais mercados mundiais para embalagens estão apresentados na Tabela 1.

O mercado de embalagens no mundo em 2000 alcançou a cifra de US\$ 431 bilhões, da qual 22\% refere-se à América do Norte; $27 \%$ à Europa Ocidental; $15 \%$ ao Japão; $5 \%$ à América Latina; e, 31\% ao resto do mundo. A participação do Brasil é de 1,65\% do mercado mundial ${ }^{[1]}$.

A produção brasileira de embalagens foi estimada em 5,5 milhões de toneladas, ou US\$ 10 bilhões, em 1998, correspondendo a $1,3 \%$ do PIB, dos quais $61 \%$ referem-se a alimentos. O setor deve crescer em torno de $35 \%$ em volume até o ano 2005 , alcançando 7,4 milhões de toneladas ou US\$ 8,7 bilhões, aos preços de 1999. Estas projeções estão baseadas no panorama atual, não considerando substituições, exceto a tendência da mudança das latas de alumínio por embalagem de poliéster (PET), no setor de bebidas ${ }^{[1]}$.

Tabela 1. Principais mercados mundiais de embalagens 1995-2005 (US\$ bilhões)

\begin{tabular}{cccc}
\hline País & $\mathbf{1 9 9 5}$ & $\mathbf{2 0 0 0}$ & $\mathbf{2 0 0 5 *}$ \\
\hline EUA/Canadá & 125,0 & 96,6 & 96,6 \\
Japão & 60,0 & 65,6 & - \\
Alemanha & 29,8 & 24,3 & 26,9 \\
França & 19,9 & 18,3 & 20,4 \\
Itália & 16,5 & 16,0 & 17,7 \\
Reino Unido & 15,0 & 13,1 & 14,7 \\
China & 14,0 & - & - \\
Brasil & 12,6 & 7,1 & 8,7 \\
Espanha & 6,4 & 7,6 & 8,6 \\
Argentina & - & 4,6 & - \\
México & 4,0 & 5,0 & - \\
Chile & 1,1 & 1,4 & 1,6 \\
Colombia & - & 1,0 & - \\
\hline
\end{tabular}

Fonte: UN, World Bank, PIRA, DATAMARK ${ }^{[1]}$

*Estimativa
Tabela 2. Segmentação do mercado de materiais de embalagem no Brasil (mil toneladas)

\begin{tabular}{ccccc}
\hline $\begin{array}{c}\text { Material de } \\
\text { embalagem }\end{array}$ & $\mathbf{1 9 9 0}$ & $\mathbf{1 9 9 8}$ & $\mathbf{1 9 9 9}$ & $\begin{array}{c}\mathbf{2 0 0 5} \\
\text { (estimativa) }\end{array}$ \\
\hline Plásticos (exceto PET) & 384 & 739 & 785 & 1.036 \\
PET & 4 & 273 & 276 & 354 \\
Papel & 298 & 301 & 311 & 377 \\
Papelão ondulado & 915 & 1.616 & 1.742 & 2.309 \\
Cartão & 234 & 390 & 376 & 439 \\
Flexíveis & 135 & 343 & 350 & 488 \\
Alumínio & 19 & 184 & 180 & 225 \\
Folhas metálicas & 584 & 668 & 668 & 778 \\
Aço & 158 & 119 & 121 & 138 \\
Vidro & 514 & 492 & 481 & 584 \\
\hline
\end{tabular}

Fonte: DATAMARK ${ }^{[1]}$

Na Tabela 2 está apresentada a segmentação do mercado de materiais de embalagem no Brasil.

A produção de plásticos no Brasil alcançou 3,4 milhões de toneladas em 1999, em comparação com 41,6 milhões de toneladas nos EUA e 26,3 milhões de toneladas na Europa (1994). Em 1998, aproximadamente $31 \%$ da produção de resina foi destinada para a produção de embalagens plásticas, transformando este setor no mercado mais importante para materiais plásticos no Brasil. $\mathrm{O}$ consumo de plásticos para embalagens nos EUA foi equivalente a $31 \%$. Estimase que o consumo de plásticos no Brasil crescerá de 3,3 milhões de toneladas em 1998 para 4,3 milhões de toneladas até $2005^{[1]}$.

\section{Contaminantes dos materiais plásticos}

Uma importante característica dos materiais plásticos utilizados como embalagem de alimentos nas operações de reciclagem é o seu comportamento termo-físico, classificados segundo o qual em termoplásticos e termofixos. A caracterização e a separação de contaminantes são ações imprescindíveis no processo de reciclagem.

Os materiais de embalagem termoplásticos caracterizam-se como produtos de reações de polimerização completas com cadeias lineares ou ramificadas. As propriedades físicas são afetadas quando submetidos ao calor e resfriamento em indefinidos ciclos, ocorrendo a formação de reduzido índice de ligações cruzadas, as quais estão associadas com a rigidez dos 
$\operatorname{mesmos}^{[2]}$. Os materiais termoplásticos compõem quase integralmente o volume dos plásticos utilizados como embalagens primárias em alimentos.

Os materiais plásticos termofixos são produtos de polimerização em que ocorre a formação de elevado número de ligações cruzadas. Quando amolecidos, pela ação do calor e resfriados, endurecem irreversivelmente, fenômeno conhecido como cura, conferindo-lhes características de extrema rigidez. As resinas epóxi e os componentes moldáveis à base de formaldeído e fenol são alguns exemplos desses materiais. Em embalagens plásticas a maior utilização de materiais termofixos é verificada na confecção e preparação de tintas, vernizes, termosselantes, adesivos, sistemas rígidos para embalagens flexíveis (tampas, sistemas de dosagem, etc.), entre outros. Em função de suas características físico-químicas, quando em composição com materiais termoplásticos de embalagens de alimentos (laminados, garrafas e potes plásticos, etc.), diminuem o valor relativo de reciclabilidade destes materiais, constituindo-se em elementos contaminantes dos mesmos.

A presença de materiais estranhos, como aço, alumínio, vidro, papel/cartão, tintas, vernizes, entre outros, utilizados nos processos de laminação e conversão de materiais plásticos com a finalidade de otimizar ou aumentar a eficiência do sistema de embalagem, constituem-se, igualmente, em contaminantes na reciclagem de embalagens plásticas ${ }^{[3]}$, bem como os resíduos de alimentos remanescentes na embalagem pós-consumo, ou sujidades adquiridas após o seu descarte.

A incompatibilidade de natureza química de determinadas resinas que compõem os diferentes materiais plásticos representam um sério problema na reciclagem de embalagens plásticas, à parte de outros contaminantes ${ }^{[4]}$.

De forma geral, quanto menor o número de componentes poliméricos e complexidade do sistema de embalagem, maior o seu valor de reciclagem, conseqüência da redução das etapas e recursos tecnológicos dispendidos no processo, como limpeza, separação dos materiais que compõe a embalagem (delaminação), recuperação de coadjuvantes utilizados na limpeza e delaminação (água e solventes) e energia necessária para estas operações ${ }^{[5,6]}$.

A reciclabilidade de embalagens plásticas está intrinsicamente relacionada com a viabilidade econômica de implementação de determinadas rotas de reciclagem. O dilema de compatibilizar a função in- trínseca do sistema de embalagem com os problemas ambientais decorrentes pelo descarte pós-consumo sem critério é um desafio para as entidades de pesquisa, empresas fabricantes de embalagens e sociedade, na viabilização de tecnologias, processos e programas que compatibilizem as vantagens da utilização de embalagem plásticas em alimentos e a sua reciclagem racional, em um contexto integrado na cadeia produção-utilização-consumo ${ }^{[7,8]}$.

\section{Fontes recicláveis de materiais plásticos}

Distingue-se, essencialmente, duas fontes recicláveis de materiais plásticos utilizados no segmento de embalagens: a industrial e o descarte pósconsumo.

Os resíduos provenientes do processo de produção industrial caracterizam-se por uma maior uniformidade de materiais, ou das frações descartadas, consequência da aplicação de procedimentos implementados na linha de produção, laminação/ conversão. Resinas, aparas de acabamento, materiais descartados por não atenderem as especificações de projeto, de qualidade, aditivos, tintas, vernizes, entre outros, constituem esta fração.

A não contaminação por resíduos do alimento, a natureza homogênea das frações, o volume concentrado a nível industrial, tornam estes resíduos com maior valor agregado de reciclagem, sob o ponto de vista empresarial, em relação aos plásticos componentes de embalagens de alimentos descartadas pós-consumo ${ }^{[9]}$.

As indústrias de produção ou conversão de embalagens visando atender os requisitos de qualificação inseridos na ISO 14000 e reduzir os custos de produção, minimizam os volumes descartáveis, através do reaproveitamento na própria linha de produção, ou otimizando o projeto da embalagem ${ }^{[2,10]}$. A venda diretamente às empresas recicladoras, além de reduzir consideravelmente o impacto ambiental, representa retorno financeiro para as empresas produtoras/convertedoras de materiais plásticos.

A reciclagem de embalagens pós-consumo caracteriza-se por um elevado nível de contaminação (orgânica e inorgânica), heterogeneidade de materiais, baixo valor relativo de reciclabilidade e alto impacto sanitário-ambiental ${ }^{[11,12]}$.

A reutilização de resinas ou materiais plásticos na própria planta de produção nas indústrias nacionais está prevista na Resolução n. 105, de 19.05.99, da Agência Nacional de Vigilância Sanitária ${ }^{[13]}$. 


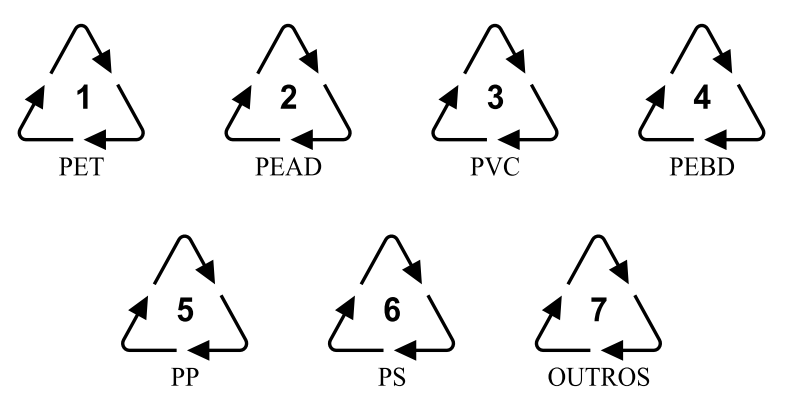

1 - Politereftalato de etileno

2 - Polietileno de alta densidade

3 - Policloreto de vinila

4 - Polietileno de baixa densidade

5 - Polipropileno

6 - Poliestireno

7 - Outros

Figura 1. Simbologia utilizada para a identificação e separação de materiais plásticos em processos de reciclagem (ABNT/NBR 13230) ${ }^{[14]}$

O sucesso na reciclagem de materiais de embalagem descartados pós-consumo ou retornáveis está estreitamente relacionado com fatores culturais, políticos e sócio-econômicos da população; a implementação de empresas recicladoras; a existência de programas de coleta seletiva, de reciclagem ou de integração com empresas recicladoras, junto às comunidades (prefeituras); a disponibilidade contínua de volumes recicláveis; o desenvolvimento de tecnologias e equipamentos compatíveis para rotas de reciclagem econômicas e tecnicamente viáveis; programas de fomento para projetos de reciclagem; redução de tributação ou isenção fiscal para a comercialização de produtos reciclados; e, sanções legais para ações ou agentes não integrados com sistemas de reciclagem na cadeia produção-utilização-consumo de embalagens.

A fim de facilitar a identificação e a separação de materiais plásticos no processo de reciclagem está regulamentada pela Associação Brasileira de Normas Técnicas $(\mathrm{ABNT})^{[14]}$ a simbologia apresentada na Figura 1, em consonância com a regulamentação internacional, devendo ser observada pelos produtores de materiais plásticos.

A caracterização para estruturas laminadas ou multicamadas cuja reciclagem é processada com a separação dos materiais constituintes é designada pela resina de maior participação na composição da embalagem. Os materiais de embalagem recicláveis sem a separação dos seus elementos integrantes (delaminação) são classificados como "outros".

\section{Opções de reciclagem de embalagens plásticas}

A reciclagem de embalagens plásticas pode ser entendida como sendo a implementação de processos e técnicas para otimizar a utilização de energia, matérias-primas, produtos e materiais empregados na fabricação de embalagens, preservando-lhe com segurança a função intrínseca quando re-destinados para a preservação de alimentos, ou sua funcionalidade como novas matérias-primas ou produtos, amparada em conceitos econômicos, sociais, sanitários e de impacto ambiental adequados.

Neste contexto, as rotas potenciais ou com viabilidade econômica disponíveis para a reciclagem de materiais plásticos podem envolver: (a) a transformação mecânica em novos materiais ou produtos; (b) a recuperação de resinas; (c) a reutilização de embalagens; (d) a transformação energética; e, (e) a degradação ambiental.

\section{Transformação mecânica em novos materiais ou produtos}

A transformação mecânica em novos materiais ou produtos, consiste em submeter os materiais plásticos a processos mecânicos, moldando-os físicamente em uma forma diferente da original. Os materiais termoplásticos, como é o caso das embalagens plásticas primárias de alimentos, adequam-se vantajosamente ao processo, preservando, em grande parte, as propriedades físicas, químicas e mecânicas dos polímeros originais ${ }^{[15]}$.

A implementação do processo prevê a coleta seletiva, limpeza de contaminantes (resíduos de alimentos, sujidades adquiridas pelo descarte pós-consumo e outros materiais incompatíveis com a natureza do material a ser reciclado), delaminação (materiais de embalagem compostos), separação e enfardamento das frações por compatibilidade de natureza polimérica. Nas unidades recicladoras os materiais selecionados são desestruturados mecanicamente. $\mathrm{Na}$ forma de particulados, são submetidos a um processo de extrusão, seguido de resfriamento brusco que, após moídos e secados, originam o material reciclado, o qual é vendido para a indústria de plásticos para a fabricação de novos produtos ou outros materiais ${ }^{[16]}$.

O principal mercado consumidor de plástico reciclado na forma de grânulos são as indústrias de artefatos plásticos, que utilizam o material na produção de baldes, cabides, garrafas de água sanitária, conduítes e acessórios para automóveis, entre outros. Os avanços técnicos de identificação e separação das diversas resinas, bem como equipamentos e tecnolo- 
gias mais modernas de reprocessamento, vêm abrindo novos mercados para a reciclagem de materiais plásticos. Além disso, a multiplicação da coleta seletiva do lixo, garantindo a oferta de material reciclável de melhor qualidade, evitando que se contamine ao ser misturado com outros resíduos, tem impulsionado o desenvolvimento do setor. Estima-se que existam no Brasil cerca de 500 instalações industriais de reciclagem de plásticos, gerando até 20 mil empregos diretos, com um faturamento de cerca de R $\$ 250$ milhões por ano, concentradas na região sul e sudeste ${ }^{[16]}$.

Os materiais plásticos de embalagem que possuem PET na sua constituição, devido à qualidade relativa intrínseca da resina, ao volume de material utilizado e ao valor agregado das embalagens, têm sido bastante visados para reciclagem, sob o ponto de vista empresarial. A sua transformação em novos materiais ou produtos incluem a produção de fibras multifilamento (fabricação de cordas) e monofilamento (produção de fios de costura); a moldagem de produtos para o setor de autopeças, lâminas para termo-formadores e formadores a vácuo, embalagens de detergentes; embalagens secundárias e terciárias de alimentos; tecidos, carpetes, pallets, entre outros ${ }^{[12,16]}$.

$\mathrm{O}$ maior problema na reciclagem de PET é sua contaminação com PVC, pois ambos submergem na separação por densidades.

Como qualquer outro processo industrial a reciclagem mecânica deve ser economicamente viável, requerendo, entre outros fatores, garantia de fornecimento contínuo de material reciclável, tecnologias apropriadas para os diferentes produtos $\mathrm{e}$ valor de comercialização para os novos produtos que compense os investimentos aplicados no processo.

\section{Recuperação de resinas}

A recuperação de resinas, também conhecida como reciclagem química, compreende a despolimerização dos materiais plásticos de embalagem, a recuperação e purificação dos monômeros originais, podendo, então, serem novamente polimerizados para a fabricação de novas embalagens plásticas primárias, ou de outros materiais ${ }^{[17-19]}$.

A recuperação de resinas de materiais plásticos para sua reutilização na fabricação de novas embalagens destinadas ao contato com alimentos, envolve a definição dos riscos associados para o consumidor, pela contaminação da embalagem com resíduos que podem migrar para os produtos acondicionados. A aprovação do uso destes materiais requer a avaliação criteriosa de riscos e do potencial de migração de possíveis contaminantes para o produto a ser acondicionado, fundamentado nos conceitos de barreira funcional e de threshold of regulation preconizados pelo FDA (Food and Drug Administration) ${ }^{[20-24]}$.

A barreira funcional é a camada íntegra da estrutura da embalagem que sob condições normais e planejadas de uso pode impedir fisicamente a difusão de migrantes para o alimento a um nível tecnicamente viável e insignificante sob o ponto de vista toxicológico e sensorial, denominado threshold of regulation, expresso no limite de exposição tolerável de até $0,5 \mathrm{ppb}$ para o consumo de substâncias de toxicidade desconhecida ${ }^{[24]}$.

A legislação brasileira ${ }^{[13]}$ (Resolução $n^{\circ}$ 105, da Secretaria de Vigilância Sanitária do Ministério da Saúde, de 19.05.99) veta a utilização de materiais plásticos procedentes de embalagens, fragmentos de objetos, materiais reciclados, ou já utilizados, à exceção do PET. Contudo, disponibiliza a utilização, em dependência de regulamentação de processos tecnológicos específicos para a obtenção destes materiais.

Alguns países do Mercado Comum Europeu, EUA e Canadá já possuem tecnologias regulamentadas para a utilização de resinas recuperadas de materiais plásticos, em embalagens de alimentos, especialmente os fabricados com $\operatorname{PET}^{[21,23]}$. A quase exclusiva concentração de estudos no desenvolvimento de tecnologias para a reutilização do PET em embalagens de alimentos, em relação a outros materiais plásticos, deve-se, à parte das qualidades intrínsecas da resina, ao valor agregado das embalagens fabricadas com este material e às suas características de baixa difusão de contaminantes ou excelentes propriedades de barreira funcional ${ }^{[25]}$.

A Portaria $n^{\circ}$ 987, de 08 de dezembro de $1998^{\text {[26] }}$, regulamenta a reutilização de resinas recicladas de PET somente para a fabricação de garrafas multicamadas destinadas ao acondicionamento de bebidas não alcoólicas carbonatadas, como constituinte de camada de barreira funcional com espessura maior que $25 \mu \mathrm{m}$ e a camada de PET recuperado menor que $200 \mu \mathrm{m}$, para produtos com a vida útil não superior a um ano, em condições de conservação inferiores ou limitadas à temperatura ambiente.

No âmbito do Mercosul, como na legislação brasileira, estão avançados os estudos para a regulamentação do uso do PET reciclado em estruturas 
multicamadas em embalagens primárias de alimentos, visando, inclusive, uma adequação da regulamentação existente com a de outros mercados comuns ou países, face o desenvolvimento e disponibilização de tecnologias compatíveis para a implementação deste processo de reciclagem ${ }^{[23]}$.

Os processos de reciclagem química de PET são caracterizados por dois tipos de empresas: (a) as que operam na valorização e descontaminação do PET oriundo de embalagens pós-consumo, ou de descarte industrial, através das operações unitárias de seleção, moagem de embalagem de PET coletadas, lavagem, secagem e cristalização dos flocos; (b) as que fabricam materiais de embalagem multicamadas com a utilização de resina PET reciclada e virgem. Os itens imprescindíveis para a consolidação e viabilidade econômica do processo depende, entre outros fatores, de: (a) instalações e equipamentos adequados para acondicionamento e processamento do PET pós-consumo, ou de descarte industrial; (b) pessoal adequadamente treinado para atuar em todas as fases do processo; (c) fluxogramas detalhados dos processos de reciclagem e fabricação de novas embalagens, com a indicação dos pontos críticos de risco e os sistemas de monitoramento adotados; (d) controle e registro das fontes recicláveis e das resinas recicladas; (e) adoção de procedimentos de controle no processo de fabricação de materiais multicamadas com a utilização de resina reciclada, visando atender e propor mudanças na legislação específica; (f) monitoramento dos resíduos do processo de reciclagem .

Um mercado igualmente promissor para a reciclagem química de embalagens plásticas pós-consumo, notadamente as de PET, é a obtenção de resinas alquídicas para utilização na produção de tintas ${ }^{[7]}$. O mercado de utilização da resina reciclada para a produção de garrafas para bebidas não alcoólicas carbonatadas multicamadas ou moldadas, tem aumentado consideravelmente, sobretudo nos Estados Unidos e Europa, em função da existência de regulamentação para a utilização de até $25 \%$ de resina reciclada na composição total da embalagem. Avanços tecnológicos na reciclagem química de plásticos, especialmente PET, bem como de mecanismos que controlem e atestem a qualidade do material reciclado indicam excelentes perspectivas na reciclagem destes materiais.

\section{Reutilização de embalagens}

$\mathrm{O}$ conceito de reutilização ou retornabilidade de embalagens de alimentos compreende a recuperação da embalagem integral pós-consumo para o desempenho da função originalmente planejada. O sistema está associado à embalagem de vidro, onde a retornabilidade (especialmente de garrafas) é tradicionalmente uma rota muito utilizada ${ }^{[27]}$.

A utilização de embalagens plásticas retornáveis está prevista e regulamentada na Resolução $\mathrm{n}^{\mathrm{0}} 105$, de 19.05.99, da Secretaria de Vigilância Sanitária / Ministério da Saúde, Anexo IX ${ }^{[13]}$, apenas para bebidas não alcoólicas carbonatadas. Além do atendimento rigoroso das condições estabelecidas para a utilização como outros materiais plásticos como embalagens primárias em alimentos, a limpeza, eliminação de contaminantes, sanitização e monitoramento do ciclo de vida útil das embalagens, devem seguir critérios rígidos de controle. Entre outras exigências, as embalagens retornáveis deverão conter em seu rótulo a expressão "uso exclusivo para ...", indicando para o consumidor/usuário o alimento para o qual é destinada.

Vários países estão revendo a legislação específica com vistas ao uso de sistemas retornáveis, especialmente para bebidas, frente aos avanços observados na fabricação de embalagens com excelentes propriedades de proteção do alimento, utilizando resinas de elevado valor agregado, como é o caso de embalagens de PET ${ }^{[28-30]}$.

A tendência de implementação de sistemas de venda de alimentos ou produtos líquidos (em supermercados, atacados, lojas de conveniência, abastecimento a domicílio, etc.), onde o consumidor reutiliza a embalagem não descartada após o consumo do produto, demonstra grande viabilidade prática de uso, com reflexos diretos no custo do produto, redução de materiais de embalagem e de matérias-primas para a sua fabricação e, conseqüentemente, do volume de materiais descartados pós-consumo.

A embalagem retornável reduz o consumo de matérias-primas virgens e diminui o impacto ambiental devido ao seu descarte pós-consumo, quando não aproveitada em outra rota de reciclagem. Apresenta, contudo, a desvantagem de exigir apreciável consumo energético no transporte e nas operações de monitoramento, controle e adequação ao ciclo de reutilização.

\section{Transformação energética}

A transformação ou reciclagem energética prevê a combustão ou pirólise dos materiais plásticos utiliza- 
dos como embalagem com a recuperação da energia liberada. Os plásticos utilizados em embalagens de alimentos, como materiais orgânicos, representam valor combustível consideravelmente positivo quando submetidos à combustão total, comparados a outros materiais.

Em geral, as misturas de plásticos encontradas nos lixos urbanos possuem um poder combustível de cerca $9.000 \mathrm{BTUs} / \mathrm{Kg}$, enquanto que nas suas frações específicas (separados de outros materiais e/ou por naturezas de plásticos) podem apresentar uma saldo energético positivo de até $42.000 \mathrm{BTUs} / \mathrm{Kg}$ de resíduo. As madeiras secas apresentam um valor energético de 12.000 a 16.000 BTUs/Kg e o carvão cerca de 24.000 BTUs/Kg. O óleo bruto do refino do petróleo possui um valor energético aproximado de $12.000 \mathrm{BTUs} / \mathrm{Kg}^{[9]}$.

Não obstante às vantagens inerentes ao processo de transformação energética, o controle e tratamento dos produtos e substâncias residuais têm concentrado estudos e críticas sob o ponto de vista ambiental.

A combustão de materiais plásticos de PVC mostra sérios problemas de corrosão de equipamentos e de poluição ambiental decorrentes da transformação do cloro contido em sua composição em produtos nocivos, tais como o cloreto de hidrogênio e dioxinas.

O cloreto de hidrogênio oriundo da decomposição térmica do PVC dissolve-se em contato com o vapor de água no processo de combustão, dando origem ao ácido hidroclorídrico, o qual é altamente corrosivo para os equipamentos que compõem o sistema de incineração.

As dioxinas (Figura 2) são compostos químicos derivados da estrutura básica $\mathrm{C}_{4} \mathrm{H}_{4} \mathrm{O}_{2}$. A substância 2,3,7,8-tetraclorodibenzo- $p$-dioxina tem sido estudada em função da sua toxicidade e efeitos deletérios em animais e seres humanos ${ }^{[2]}$.
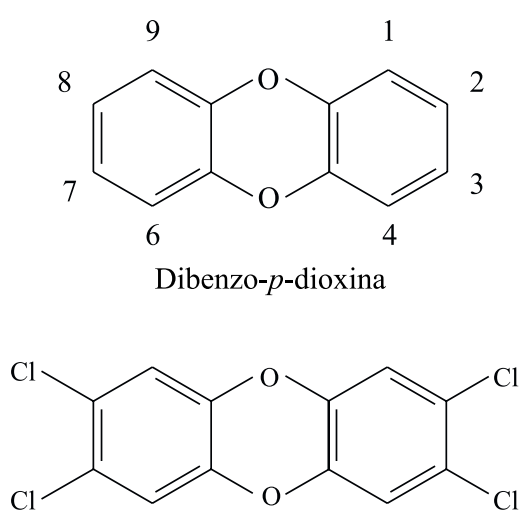

2,3,7,8 - Tetraclorodibenzo- $p$-dioxina

Figura 2. Estrutura química de dibenzo- $p$-dioxina e 2,3,7,8 tetraclorodibenzo-p-dioxina
Além das dioxinas, outros compostos da decomposição térmica do PVC, como furanos e ftalatos, têm sido recentemente estudados pelos seus efeitos nocivos e formação de compostos de prolongada persistência no meio ambiente. Estes problemas vêm comprometendo a utilização do PVC em materiais de embalagem e outros materiais, apesar de suas excelentes características de maquinabilidade e baixo custo relativo comparado com outras resinas.

Da mesma forma, a presença de materiais pesados como cádmio, cromo, zinco e, especialmente, mercúrio, quer nas emissões gasosas ou no resíduo sólido (cinzas), requerem a implementação de controles eficientes de neutralização, separação ou recolhimento dessas substâncias, sob pena de comprometer a estrutura e equipamentos de incineração e pirólise, assim como a viabilidade do processo.

A pirólise é uma opção de transformação energética de materiais plásticos que envolve a decomposição térmica parcial, originando óleo combustível bruto, o qual pode ser utilizado como fonte de energia, via combustão, ou transformado em outros produtos ou materiais. Como vantagens relativas do processo em relação à combustão podem ser destacadas: (a) a possibilidade de armazenamento, transporte e utilização como óleo bruto; (b) a viabilidade de refino do óleo bruto para a obtenção de monômeros para síntese de outros produtos plásticos; (c) a transformação do óleo bruto para composição de materiais com aplicação na construção civil (isolante, impermeabilizante, etc.) e como componente de material asfáltico na construção de rodovias.

Os processos de transformação energética (combustão e pirólise) representam uma redução significativa do volume de materiais de embalagem pós-consumo lançados sem destinação racional no meio ambiente ou em aterros sanitários, para os quais não exista processos de reciclagem apropriados. Também, permite uma redução considerável da utilização de outras fontes de matérias-primas não renováveis, tradicionalmente utilizadas para obtenção de energia, como é o caso do óleo combustível extraído do refino do petróleo, ou a queima de madeira.

$\mathrm{O}$ requerimento de equipamentos e instalações apropriados para os processos, o controle e monitoramento das emissões gasosas, dos resíduos sólidos e das frações decompostas na degradação térmica, de modo a representar um retorno ou ganho energético positivos e uma redução de impacto ambiental que jus- 
tifique economicamente os processos utilizados, são os principais fatores críticos da reciclagem térmica.

A combustão e/ou pirólise de materiais plásticos têm sido implementados com relativa eficiência em países com elevada densidade populacional, com restritas opções de fontes energéticas convencionais e com disponibilidade de recursos para a viabilização de tecnologias para a aplicação e controle destes processos.

\section{Degradação ambiental}

Os plásticos são considerados substratos inertes, com índices de decomposição variáveis (quase desprezíveis) por elementos ambientais, como luz, umidade, calor e microrganismos. Quando degradados podem originar substâncias não inócuas, de prolongada persistência e de restrito controle ambiental.

A não degradabilidade no ambiente de materiais plásticos pós-consumo tem sido um dos fatores em que ambientalistas têm centrado suas campanhas em detrimento das vantagens e dos avanços obtidos na utilização de resinas plásticas para o desenvolvimento de embalagens para alimentos ${ }^{[31]}$. Por outro lado, a pesquisa e o planejamento de embalagens com componentes que favoreçam a sua degradação ambiental é um desafio e um dilema para estes setores, pois envolvem itens que se contrapõem à função primordial da embalagem de proteção e manutenção da estabilidade de alimentos.

Para aumentar os índices de degradação no meio ambiente, várias propostas têm sido estudadas, com limitada aplicabilidade econômica, até o momento, entre as quais: (a) a incorporação de elementos na estrutura da embalagem que promovam processos de fotodegradação (fotossensibilizantes, sais metálicos, nitrocompostos, quinonas, benzofenóis, entre outros); (b) o estudo de utilização de estruturas poliméricas (poliamidas, poliésteres, poliuretanos) que contenham estruturas hidrofílicas na sua composição, predispondo-as à degradação pela ação da umidade do ambiente; (c) o desenvolvimento de materiais mistos de embalagem a base de polímeros sintéticos com amidos modificados, ou com outros polímeros que apresentem suscetibilidade natural para o ataque de microrganismos no ambiente ${ }^{[32]}$.

\section{Aspectos legais}

Um dos grandes desafios para as indústrias de embalagens, frente à competitividade globalizada no setor, tem sido o atendimento às certificações ISO
9000 (gestão da melhoria da qualidade) e, atualmente, ISO 14000, que considera a gestão ambiental dos processos produtivos, além dos parâmetros de qualidade.

Dois conceitos fundamentais são considerados nos critérios de certificação para a ISO 14000 de empresas fabricantes, ou utilizadoras de embalagens: a rotulagem ambiental e a análise de ciclo de vida do produto.

A rotulagem ambiental releva informações acuradas ao consumidor a respeito do impacto ambiental de um produto ou serviço. Tem por objetivo promover a redução das implicações ambientais negativas relacionadas a produtos e serviços, através da conscientização de fabricantes, consumidores e instituições públicas sobre as vantagens de optar por produtos e serviços que causem o menor dano ambiental possível, durante o seu ciclo de vida. Até o momento estão implementadas as normas ISO Tipo 1 (14024) Selos Verdes / Certificação porTerceiros e Tipo 2 (14021) Auto Declaração ${ }^{[8]}$.

A análise do ciclo de vida de um produto ou serviço (Life Cycle Assessment) compatibiliza os impactos ambientais decorrentes de todas as etapas envolvidas, desde a sua concepção mercadológica, planejamento, extração e uso de matérias-primas, gasto de energia, transformação industrial, transporte, consumo; até o seu destino final (no caso de embalagens), pela disposição destas em aterro sanitário, ou a sua reciclagem. Igualmente, o monitoramento de aspectos indiretos envolvidos com estas etapas do processo são relevantes, como a identificação e quantificação das emissões gasosas, o tratamento de efluentes e resíduos sólidos finais.

As principias vantagens decorrentes da utilização da análise do ciclo de vida no setor de embalagens são: (a) a visão sistêmica do setor em relação ao impacto ambiental; (b) propiciar a identificação das partes críticas da produção e do uso, orientando as ações voltadas à melhoria do sistema; (c) sensibilizar todos os componentes do sistema para os problemas ambientais envolvidos; (d) oferecer elementos para a orientação de discussões no âmbito sistêmico do processo, em detrimento a pontos específicos; (e) proporcionar informações básicas para a discussão e avaliação de assuntos ambientais.

$\mathrm{O}$ conceito de eco-eficiência também vem sendo adotado por empresas do mundo inteiro, como apelo para assegurar que seus sistemas de produção, produtos 
e serviços estão comprometidos com uma performance econômica e ambiental corretas. Nesse sentido, a empresa que busca a eco-eficiência passa a adotar condutas como a minimização do consumo de matérias-primas virgens e sua substituição por materiais reciclados; concentra esforços para diminuir a toxicidade de seus produtos, aumentando-lhes sua vida útil; reduz o gasto de energia em seus processos, entre outros ${ }^{[17]}$.

As conceituações de análise do ciclo de vida e de rotulagem ambiental, notadamente, são elementos já observados e exigidos em muitos mercados e legislações internacionais de embalagens de alimentos, merecendo rigorosa avaliação nos setores de produção, comercialização de produtos/alimentos e reciclagem, sendo definitivamente seletivos para o sucesso ou a inviabilização de empreendimentos envolvidos direta ou indiretamente com o setor de embalagem e conservação de alimentos.

\section{Considerações finais}

A utilização e a consolidação de materiais plásticos como embalagens de alimentos mostra indiscutíveis vantagens em relação a outros tipos de materiais. O volume descartado de embalagens plásticas pósconsumo no ambiente sem destinação racional, tem preocupado a sociedade quanto ao ajuste, implementação e adequabilidade de intervenções, notadamente sob os aspectos social, econômico e sanitárioambiental, ponderado o seu excelente desempenho e vantagens como embalagens de alimentos.

$\mathrm{O}$ aproveitamento dos materiais plásticos após a sua utilização como embalagem de alimentos deve ser proposta como uma atividade empresarial economicamente viável integrada em todos os setores da sociedade, em vista dos volumes envolvidos, da economia e racionalização de recursos naturais nãorenováveis, da energia e valor agregados nos materiais e do impacto ambiental causado pelo seu descarte não racional pós-consumo.

A reciclagem de materiais plásticos de embalagem pós-consumo, pela transformação em outros produtos, deve ser uma opção melhor explorada nas condições brasileiras, face os volumes disponíveis, possibilidade de aplicabilidade de tecnologias menos sofisticadas, amplo espectro de materiais disponíveis, existência de demanda e aceitabilidade no mercado interno de produtos fabricados com materiais reciclados e representar uma rota empresarialmente viável e ecologicamente correta.
A reutilização ou retornabilidade de embalagens, a recuperação de resinas constituintes de materiais plásticos, a transformação energética, nessa ordem, apresentam-se como processos de reciclabilidade de materiais plásticos com empenho contextualizado mundialmente, demandando regulamentação pertinente, implementação de tecnologias adequadas e ambientalmente seguras, bem como de esforços integrados de governos, sociedade, órgãos de pesquisa e empresas.

Os conceitos de degradabilidade ambiental e análise do ciclo de vida devem ser considerados no desenvolvimento de novos materiais e na planificação de embalagens plásticas primárias de alimentos, considerado o dilema entre a eficiência preconizada para a embalagem como fator de conservação do alimento e a compatibilização de fatores que predisponham e acelerem sua degradação ambiental pós-consumo.

Programas integrados de fomento à reciclagem devem considerar incentivos aos sistemas de coleta seletiva, isenção de tarifas e impostos na comercialização de produtos reciclados e sanções legais aos agentes ou ações que comprometam o sistema, sob o ponto de vista social, técnico e sanitário-ambiental.

\section{Referências Bibliográficas}

1. Wallis, G. - "A evolução do mercado brasileiro de embalagem e sua inserção no mercado internacional", in: Anais Brasil Pack Trends 2005 Seminário Embalagem, Distribuição e Consumo, Campinas-SP (2000).

2. Selke, S.E.M. - "Packaging and the enviroment - alternatives, trends and solutions". Lancaster, England (1990).

3. Huber, M. \& Franz, R. - Deutsche Lebensmittel Rundschau, 93(10), p.328 (1997).

4. Briston, J. H.\& Katan, L.L. - "Plastics and the Environment", in: Plastics in Contact with Food. Anchor Press, London (1974).

5. Sadler, G.D. - "Recycling of Polymers for Food Use: a Current Perspective", in: Plastics, Rubber, and Paper Recycling: a Pragmatic Approach. American Chemical Society, Washington (1995).

6. Tacito, L.D. - "Polymer Recycling Technology for Food Use Technical Requirements to Meet Safety and Quality Assurance”, in: American Chemical Society, Washington (1995). 
7. Associação Brasileira dos Fabricantes de Embalagens de PET (ABEPET) \& Compromisso Empresarial para Reciclagem (CEMPRE) - "Reciclagem \& Negócios - PET”, CEMPRE, São Paulo (1997).

8. Madi, L.; Müller, M. \& Wallis, G. - "Brasil Pack Trends 2005 - Tendências da Indústria Brasileira de Embalagem na Virada do Milênio", CETEA/ITAL, Campinas (1998).

9. Brown, W.E. - "Package disposal", in: Plastics in Food Packaging - Properties, Design and Fabrication, cap.12, Marcel Dekker, New York (1992).

10. Widden, H. - SIK-Rapport, 646, (1998).

11. Begley, T.H. \& Hollifield, H.C. - "Food Packaging Made from Recycled Polymers: Funcional Barrier Considerations", in: Plastics, Rubber, and Paper Recycling: a Pragmatic Approach, American Chemical Society, Washington (1995).

12. Instituto de Pesquisas Tecnológicas (IPT) / Laboratório de Embalagem e Acondicionamento (LEA) - Revista Embalagem \& Cia, 107, p.34 (1997).

13. Ministério da Saúde / Agência Nacional de Vigilância Sanitária. Regulamento Técnico - Disposições Gerais para Embalagens e Equipamentos Plásticos em Contato com Alimentos. Resolução n. 105, de 19 de maio de 1999 - Diário Oficial da União, 20 de maio (1999).

14. Associação Brasileira de Normas Técnicas (NBR) "NBR 13230 - Reciclabilidade e identificação de materiais plásticos".

15. Garcia, E.E. - Boletim Técnico do Centro de Tecnologia de Embalagem, 10 (1), p.8 (1998).

16. Compromisso Empresarial para Reciclagem (CEMPRE) - Disponível na Internet: http:www. cempre.org.br (2001).

17. Crockett, C. \& Sumar, S. - Nutrition and Food Science, 4, p.34 (1996).

18. Franz, R. - Verpackungs Rundschau, 48, p.34 (1997).

19. Franz, R.; Huber, M. \& Welle, F. - Deutsche Lebensmittel Rundschau, 94 (9), p.303 (1998).
20. Bayer, F.L. - Food Additives and Contaminants, 14 (6/ 7), p.661 (1997).

21. Jetten, J; Kruijf, N. de \& Castle, L. - Food Additives and Contaminants, 16(1), p.25 (1999).

22. Stelmach, A.; Cwiek-Ludwicka, K.; Jurkiewicz, J.; Mazanska, M. - Przemysl Spozywczy, 53(8), p. 6 (1999).

23. Freire, M.A.F.; Reyes, F.G.R.; Kusnesof, P.M. \& Vettorazzi, G. - Polímeros:Ciência e Tecnologia, (4), p.42 (1998).

24. Bayer, F. - Food Additives and Contaminants, 14 ( $6 /$ 7), p. 661 (1997).

25. Goddard, R.R. - European Food \& Drink, 57(59/61) (1996).

26. Ministério da Saúde / Agência Nacional de Vigilância Sanitária. Regulamento Técnico - Embalagens Descartáveis de Polietileno Tereftalato - PET Multicamada Destinadas ao Acondicionamento de Bebidas não Alcoólicas Carbonatadas. Portaria n. 987, de 8 de dezembro de 1998 - Diário Oficial da União (1998).

27. Kruijf, N. de - Food Technology International Europe, p.85 (1997).

28. Bertin, J. - European Food \& Drink, p.57 (1998).

29. Komolprasert, V. \& Lawson, A.R. - Journal of Agricultural and Food Chemestry, 45(2), p.444 (1997).

30. Schlenker, R.; Thoma, S. \& Oechsle, D. - Brauwelt, 139(18), p.794 (1999).

31. Kuznesof, P.M. \& Vanderveer, M.C. "Recycled Plastics for Food-contact Applications: Science, Policy, and Regulation", in: Plastics, Rubber, and Paper Recycling: a Pragmatic Approach. American Chemical Society, Washington (1995).

32. Lomas-Eesteban, M.C. - Alimentacion Equipos y Tecnologia, 15(1), p.39 (1996).

Recebido: 15/12/01

Aprovado: 10/04/02 